\title{
Immunological Abnormalities in Autism Spectrum Disorders
}

\author{
Harumi Jyonouchi* \\ Department of Pediatrics, Rutgers-New Jersey Medical School (NJMS), Newark, NJ, USA
}

\begin{abstract}
Secondary to clinical features indicating chronic inflammation and immune dysregulation, the immune system has long been suspected to have a role in autism spectrum disorders (ASD). Studies of postmortem autistic brains indicate the presence of immune mediated chronic inflammation in some but not all autistic brains. However, studies of immune abnormalities in ASD children yielded no conclusive results. Instead, immune abnormalities reported appear to affect almost all aspects of the immune system and are often contradictory. This may be associated with the marked heterogeneity of ASD subjects, since ASD is a behaviorally defined syndrome. In addition, variable co-morbid conditions could affect the immune-parameters, making such analysis very difficult. Alternatively, various immune abnormalities reported may be associated with the fact that ASD is a polygenic condition affected by multiple genetic and environmental factors, resulting in similar behavioral symptoms. At present, it is unknown how the immune system contributes to the onset and progress of ASD. Nevertheless, the results of previous studies indicate the presence of chronic inflammation, in at least a portion of ASD children. This review summarizes previous immunological findings and the problems associated with these studies. The direction that future research needs to take will also be discussed.
\end{abstract}

Keywords: Autism spectrum disorders (ASD), immune system

\section{ABBREVIATIONS USED}

Ab, antibody

$\mathrm{ABC}$, Aberrant Behavior Checklist

$\mathrm{Ag}$, antigen

APC, Ag presending cells

AS, ankylosing spondylitis

ASD, autism spectrum disorder

ASD-IS, ASD-inflammatory subtype

BMDM cells, bone marrow derived microglial cells

C, complement

C1q, complement factor 1q

CNS, central nervous system

FA, food allergy

FHR1, complement factor $\mathrm{H}$ related protein 1

GD, gestational day

\footnotetext{
${ }^{*}$ Correspondence to: Harumi Jyonouchi, M.D., F570A, MSB, Pediatrics, Rutgers-NJMS, 185 South Orange Ave, Newark, NJ 07101-1709, USA. Tel.: +1 973972 1414; Fax: +1 973972 6843; E-mail: jyanouha@njms.rutgers.edu.
}

$\mathrm{GH}$, growth hormone

GI, gastrointestinal

GM-CSF, granulocyte monocyte colony stimulating factor

GPX, glutathione peroxidase

GSH, glutathione

GWAS, genome wide association study

HLA, human leukocyte antigen

HSC, hematopietic stem cells

HSP70, heat shock protein 70

ICAM-1, intercellular adhesion molecule-1

IFN, interferon

Ig, immunoglobulin

IGF, insulin like growth factor

IGFBP, IGF binding protein

IL, interleukin

IL-1ra, IL-1 receptor antagonist

IVIG, intravenous immunoglobulin

KIR, killer-cell immunoglobulin-like receptor

LI, latent inhibition 
LPS, lipopolysaccharide

MDCs, myeloid dendritic cells

MHC, major histocompatibility complex

MIA, maternal immune activation

Mo, monocyte

MRI, magnetic resonance imaging

MS, multiple sclerosis

mtDNA, mitochondrial DNA

NFA, non IgE mediated food allergy

NK, natural killer

NJMS, New Jersey Medical School

NT, neurotensin

$\mathrm{PB}$, peripheral blood

PBMCs, peripheral blood mononuclear cells

PDCs, plasmacytoid dendritic cells

PECAM-1, platelet endothelial cell adhesion molecule - $1 \mathrm{Th}$, T-helper

PMA, phorbol 12-myristate 13-acetate

PPA, propionic acid

PPI, prepulse inhibition

SCFA, short chain fatty acid

TGF, transforming growth factor

Th, T-helper

TLR, toll like receptors

TNF, tumor necrosis factor

Treg cells, regulatory $\mathrm{T}$ cells

VEGF, vascular endothelial growth factor

\section{INTRODUCTION}

Except for a small subset of ASD children with known gene mutations, autism spectrum disorder (ASD) is a behaviorally defined syndrome associated with multiple gene mutations and environmental factors [1-3]. Consequently, as the name implies, ASD is characterized by varying clinical phenotypes, a lack of definitive laboratory diagnostic measures, and a high frequency of co-morbidities. Gastrointestinal (GI) symptoms have been recognized as one of the most common co-morbidities $[4,5]$. Other co-morbidities that have been reported by some parents of ASD children include adverse reactions to multiple medications, recurrent infection, and so-called 'allergy' symptoms. The GI symptoms frequently observed in ASD children are sometimes referred to 'autism colitis' and some researchers implicate autoimmune conditions as the cause of GI symptoms [6].

Because of the above described clinical features, the immune system has been suspected of having a role in the onset and/or development of ASD and various immune-parameters have been studied in ASD children. However, the immune abnormalities that have been reported in ASD children affect almost all arms of the immune system, albeit subtly, and are not attributed to one specific immune pathway. Moreover, the previous studies of immune-parameters in ASD children often have yielded conflicting results, making it difficult to assess the role of the immune system in ASD. Consequently, these results have not been applicable for diagnosis, subgrouping, or assessment of the disease outcome/treatment options in ASD.

Such inconsistent results are partly attributed to the inclusion of markedly heterogeneous ASD subjects. That is, in most of the studies, study subjects are characterized based on behavioral symptoms and developmental assessments. In our experience, clinical features indicating immune abnormalities are observed only in a portion of ASD children. Therefore, categorizing ASD subjects on the basis of allergy/immunology evaluations (for phenotyping) might be helpful in such studies [7, 8]. The variable and conflicting immunological results in ASD subjects discussed later in this review may also be attributed to the fact that most of the studies were cross-sectional, with no assessment of the reproducibility of the results. Relatively small numbers of study subjects with varying ages may also be a factor causing conflicting results. It is well known that certain immune-parameters change with age. In addition, previous immune studies were often done with little consideration of co-morbid conditions that might have affected the results of immunological evaluations, as well as their behavioral symptoms.

It is only recently that research efforts have begun to assess the association between manifestation and severity of the clinical features of autism and certain immune-parameters. However, in most studies, such analysis has been challenging. This is again attributed, in part, to the inclusion of heterogeneous ASD subjects, inadequate allergy/immunology evaluations, and the lack of consideration of the effects of co-morbid conditions that may affect behavioral symptoms and cognitive activity. Alternatively, this may be reflecting the fact that the nervous and the immune systems are regulated by multiple common pathways and changes in multiple genetic and environmental factors that affect these pathways may result in similar clinical features as observed in other polygenic medical conditions. In summary, conflicting results in 'immune studies' indicate a need for objective biomarkers that will help subcategorizing ASD children. 
In this review paper, I will discuss previous studies that focused on immune abnormalities associated with adaptive immunity (humoral immunity, $\mathrm{T}$ cell mediated immunity, Antigen (Ag) presenting cells (APC)), and innate immunity in ASD children. Weakness of the studies and possible underlying causes of conflicting results reported in previous studies will also be discussed. In the latter part of this review, studies focusing on chronic inflammation and maternal immune activation (MIA) in ASD will also be discussed. Finally, chronic GI inflammation in ASD children will also be discussed, along with the need for subgrouping of ASD children on the basis of clinical/immunological evaluation when assessing the role of the immune system in ASD.

\section{Adaptive immunity}

\section{I-a Humoral immunity}

Studies regarding humoral immunity in ASD children have focused on two areas, assessment of humoral immune dysfunctions and the role of autoantibodies, including maternal autoantibodies. A possible role of maternal autoantibodies has been assessed in association with MIA during fetal life and resultant aberrant immune responses in ASD children. MIA will be discussed later in this review (in Section III).

\section{Studies of possible humoral immune dysfunction:}

- Decreased levels of serum immunoglobulin G (IgG) and $\operatorname{IgM}$ were reported in autistic children $(N=116)$ at $2-4$ years of age, as compared to age-matched typically developing children $(N=96)$ [9]. In addition, an inverse association between behavioral symptoms assessed by Aberrant Behavior Checklist $(\mathrm{ABC})$ and $\mathrm{IgG} / \mathrm{IgM}$ levels was noted [9]. However, ASD subjects who exhibited low $\mathrm{IgG} / \mathrm{IgM}$ levels at 2-4 year-old revealed within normal levels of $\operatorname{IgG} / \operatorname{IgM} 2$ years later and they did not reveal functional or phenotypic abnormalities of B cells when 73 subjects were tested in a follow up study [10].

- Grether et al. studied levels of Ig isotypes, specific antibodies, and C-reactive protein (CRP) in archived blood samples obtained for newborn screening in children later diagnosed with ASD $(N=213)$ and normal controls $(N=265)$ [11]. Lower IgG levels were found to be associated with risk of developing ASD [11]. Authors proposed that this finding was indicative of maternal immune dysfunction during pregnancy, since
IgG detected shortly after birth are maternal IgG transferred through placenta.

- Ig levels and CD23 expression on B cells were studied in 24 ASD children (Age: 3-6 years) in comparison with age and sex matched controls $(N=24)$. Authors reported that higher $\mathrm{IgE} / \mathrm{IgG}$ and lower IgA levels were associated with the diagnosis of regressive autism along with increased numbers of $\mathrm{CD} 23^{+} \mathrm{B}$ cells [12].

- Higher levels of IgG2/IgG4, total protein, albumin, and $\gamma$-globulin were reported in autistic children [13]. Authors attributed these findings to underlying autoimmune conditions but this was conducted in a small number of subjects of older ages (13-19 yrs) (18 autistic subjects vs. 22 normal controls) [13].

- Wei et al. reported down regulated signaling of focal adhesion kinase-Src complex in B lymphoblasts derived from autistic children $(N=8)$ [14].

In the above described studies, it is unclear whether the autistic children with lower IgM/IgG exhibited any clinical features that are typically associated with low Ig levels, such as frequent respiratory infection. It may be speculated that temporary decreased levels of $\mathrm{IgG} / \mathrm{IgM}$ can cause frequent infection, resulting in worsening behavioral symptoms. In our experience, $\mathrm{ABC}$ scores are affected by co-morbid conditions, such as recurrent infection partly due to pain and discomfort associated with recurrent infection, as reviewed previously [15].

As described above, studies by Croonebergh et al. and Wasilewska et al. yielded higher levels of $\operatorname{IgG}$ in ASD subjects, as opposed to lower levels of $\mathrm{IgG} / \mathrm{IgM}$ in the studies by Grether et al. and Heuer et al. This may be associated with the small number of study subjects, difference in ages of the study subjects, as well as the marked heterogeneity of ASD subjects. Studies reported by Wei et al. used cell lines derived from eight autistic patients and no information was provided regarding their clinical features of these ASD subjects.

Based on the studies described above, it is unclear whether Ig levels in young ASD children (2-4 years) will be helpful in identifying specific subpopulations of ASD or assessing disease outcome. Longitudinal evaluation of Ig levels in ASD children with consideration of their clinical features is likely required for addressing a question of whether Ig levels or other B cell functions can be biomarkers in ASD. It should also be noted, that in ASD children $(N=8)$ with clinical features characterized by frequent infection, persistent GI 
symptoms, and adverse drug reactions, we observed a gradual decline of total IgG and antibody titers for polysaccharide antigens over several years [16]. These children eventually became qualified for supplemental intravenous immunoglobulin (IVIG) [16]. These children did not reveal low IgG or IgM levels at 2-4 years of age.

\section{A role of autoantibodies:}

The possibility that autoantibodies play a role in ASD has attracted significant attention and the presence of autoantibodies against multiple neuronal proteins have been reported in ASD children, as summarized elsewhere [17]. Many of these autoantibodies are against brain proteins including myelin basic protein [18], nerve growth factor [19], brain endothelium [20], and transglutaminase 2 which has a key role in synaptic stabilization [21]. In addition, autoantibodies against uncharacterized brain-specific proteins have been reported [17]. Results of recent representative studies focused on autoantibodies are summarized as follows:

- Cabnlit et al. reported a higher frequency of autoantibodies against proteins in the thalamus and hypothalamus (52 kDA) and in the hypothalamus (43-48 kDA) of adult brains in autistic children $(N=63$, median age: $43 \mathrm{mo})$, as compared to age-matched controls $(N=63)(30 \%$ vs. $11 \%$ and $37 \%$ vs. $13 \%$, respectively) [22].

- Goines et al. reported a positive association between presence of autoantibodies to a $45 \mathrm{kDA}$ cerebellar protein and autism diagnosis in a study of 277 ASD children and age-matched typically developing children $(N=189)$ [23]. Authors also reported a positive association between autoantibodies to a $62 \mathrm{kDA}$ cerebellar protein and a broader diagnosis of ASD as well as an association between the presence of such autoantibodies and lower adaptive/cognitive functions and core autistic behaviors [23].

- In a follow up study by Goines et al. such anticerebellar antibodies were reported to be targeting GABAergic neurons when studied in 7 ASD subjects who have autoantibodies against $52 \mathrm{kDA}$ cerebellar proteins [24].

It should be noted, that although autoantibodies may serve as biomarkers for a portion of ASD children, possibly reflecting underlying autoimmune conditions and/or CNS inflammation, these autoantibodies may not be pathogenic. That is, many autoantibodies are formed as an epiphenomenon in patients with immune dysfunction and chronic inflammation. If the autoantibodies are pathogenic, a positive association between markers of CNS damage and serum autoantibodies in ASD children would be seen. One recent study reported a higher serum levels of $\mathrm{S} 100 \mathrm{~B}$, a marker of CNS inflammation, in autistic children $(N=64)$, but authors reported a lack of association between serum levels of S100B protein and anti-ribosomal $\mathrm{P}$ protein antibodies, which were high in children with severe autism as compared to controls [25] This study indicates that anti-ribosomal $\mathrm{P}$ protein antibodies detected in ASD children may not be pathogenic.

Recent interest in this field has also focused on maternal autoantibodies against fetal brains, which may be a biomarker for dysregulated maternal immune activation (MIA) during pregnancy.

- Autoantibodies against a $39 \mathrm{kDA}$ protein of fetal brains were reported to be present at higher frequencies in mothers with autistic children $(N=100)$ than in control mothers without autistic children $(N=100)(10 \%$ vs. $2 \%)$ [26]. It should be noted, that in this study, the maternal serum samples were obtained over 10 years after delivery of ASD and control children.

- Utilizing sera obtained from prenatal-screenings during mid-gestation, Croen et al. reported that mothers with autistic children $(N=84)$ have a higher frequency of autoantibodies against a $39 \mathrm{kDA}$ fetal brain protein than control mothers randomly selected from general population $(N=160)(7 \%$ vs. $2 \%)$ [27].

- In a study of 202 mothers of ASD children, functional MET (proto-oncogene product) promotor variant rs1858830C allele was reported to be positively associated with the presence of autoantibodies against 37 and $73 \mathrm{kDA}$ fetal brain proteins [28]. The authors attribute this finding to lower expression of MET proteins and lower production of IL-10 by peripheral blood mononuclear cells (PBMCs) in those with this variant [28].

- Maternal IgG antibodies against fetal brain proteins (37 and $73 \mathrm{kDA}$ ) was found to be positively associated with the diagnosis of autism and lower expressive language scores when tested in 204 autistic and 71 ASD children in comparison with 183 typically developing and 102 developmentally delayed non-autistic children [29]. The authors also reported that the presence of these IgG autoantibodies are positively associated with the broader diagnosis of ASD and increased 
irritability by $\mathrm{ABC}$ [29]. Authors reported that such autantibodies were found in about 10-12\% of ASD children and none found in control children [29].

- The same group recently reported that purified IgG from mothers of autistic children caused anxiety and delayed development in a mouse gestational transfer model; in this study, a low dose of IgG from mothers of autistic children $(N=3)$ was given at one time point during gestation [30]. Control $\mathrm{IgG}$ was obtained from mothers with typically developing children $(N=3)$.

- Bauman et al. also tested the effects of $\operatorname{IgG}$ isolated from mothers of children with ASD $(N=4)$ and those of typically developing children $(N=8)$ on pregnant monkeys $(N=8)$ [31]. Authors reported enlarged brain volume and altered social behaviors in offspring from monkey mothers treated with ASD-IgG; enlarged brain volume was detected only in a male offspring in a follow- up study of 2 year period [31].

- One study reported presence of IgG autoantibodies against fetal brain (37/73 kDA) in 10 out of 131 autistic children. Authors report that the presence of $\operatorname{IgG}$ autoantibodies was associated with abnormal brain enlargement [32].

- Braunschweig et al. reported exclusive reactivity to specific antigen combinations in fetal brain of Rhesus Macaque in $23 \%$ of mothers of ASD children $(N=246)$ while this was only detectable in $1 \%$ of control mothers with non-ASD children $(N=146)$ [33]. Maternal autoantibodies detected were those targeting lactate dehaydrogenase A and B, cypin, stress-induced phosphoprotein 1, collapsing response mediator proteins 1 and 2, and Y-box-binding protein [33]. However, it should be noted that autoantibodies detected in ASD mothers are against combinations of some of these antigens, that is, autoantibodies detected in each ASD mother varied with regard to target antigens.

These findings indicate that maternal autoantibodies may be biomarkers of maternal immune dysregulation during pregnancy. However, it remains to be seen whether any specific autoantigen (s) are associated with ASD pathogenesis, or this is reflecting epiphenomena. In addition, the fact that such autoantibodies can also be detected in mothers without ASD children, albeit at lower frequencies, indicates the complex pathogenesis of ASD and the involvement of other genetic and environmental factors. At least, presence of maternal autoantibodies may be a biomarker of MIA in a portion of ASD children. Therefore, further phenotypical characterization of ASD children born to mothers with positive maternal autoantibodies are expected to be informative. Such phenotypical characterization should include evaluation of allergy/immunology disorders and other co-morbid conditions. This is based on the assumption that if maternal autoantibodies are associated with MIA, immunodysregulated conditions such as impaired oral tolerance or adverse reactions to medications, can be more frequently seen in ASD children born to mothers with positive autoantibodies.

\section{I-b T cell functions}

Because some ASD children present with clinical features associated with immunodeficiency and immunodysregulation, $\mathrm{T}$ cells, key regulators of the immune system, have also been investigated in ASD children. In earlier studies, one study reported increased numbers of circulating type $2 \mathrm{~T}$-helper (Th2) cells (IL-4 ${ }^{+} \mathrm{CD} 4^{+}$cells) [34], while others reported increased plasma levels of Th1 cytokines in ASD children [35]; in both studies, only 20 autistic and 20 control children were studied. In our previous studies, we did not detect any specific trend of Th responses or increased prevalence of atopic conditions typically associated with skewed Th2 responses in 133 ASD children [7]. Such conflicting results in earlier studies can be attributed to the use of small number of markedly heterogeneous ASD subjects, and the lack of careful characterization of the study subjects from the view of allergy and immunology. The results of more recent studies of $\mathrm{T}$ cell immunity in ASD children are summarized as follows:

- The study of immune-phenotyping of peripheral blood mononuclear cells (PBMCs) in young autistic children (Age 4-7 years, $N=70$ ) and agematched control children $(N=35)$ revealed no difference in absolute numbers of T cells between the study groups but higher expression of $\mathrm{T}$ cell activation markers (HLA-DR, CD26) in ASD children than controls [36]. Authors also reported higher numbers of $\mathrm{B}$ and natural killer (NK) cells in the ASD group [36]; this result as well as higher expression of activation marker (CD28) on B cells appear to contradict the report of no abnormalities of B lineage cells in ASD children by the same group [10].

- In ASD children (Age: 2-5 years, $N=66$ ) and agematched control children $(N=73)$, it was reported that PBMCs from ASD children had increased 
production of granulocyte-macrophage colony stimulating factor (GM-CSF), tumor necrosis factor- $\alpha$ (TNF- $\alpha)$, and interleukin-13 (IL-13), but decreased production of IL-12 in response to phytohemagglutinin (PHA), T cell mitogen, along with altered expression of $\mathrm{T}$ cell activation markers (CD134 and CD25), as compared to controls [37]. As the authors implied, these results may indicate Th2 skewed responses in the ASD subjects. However, TNF- $\alpha$ is not typically associated with Th2 responses but more commonly implicated with Th1 responses [38]. Authors also reported a positive association between production of higher amounts of TNF- $\alpha$ and INF- $\gamma$ (a representative Th1 cytokine,) and greater impairments in core features of ASD and aberrant behaviors [37]. Their results may indicate that increased Th1 cytokine production is associated with worsening ASD symptoms.

- Another study by Ashwood et al. examined plasma cytokine levels in 97 ASD children (Age: 2-5 years) in comparison with age-matched typically developing children $(N=85)$. Authors report higher plasma levels of IL-6, IL-1 $\beta$, IL-8, and IL-12 in ASD children [39]. These results are contradictory to the results of the study by the same group described above, since these cytokine elevated in the plasma are known to be associated with Th17 and Th1 responses but not skewed Th2 responses [40]. The authors reported a positive association between increased levels of these cytokines and regressive forms of autism as well as impaired communication and aberrant behaviors [39].

- Manzardo et al. studied plasma cytokine levels in 99 ASD children (Age 5-10 years of age) in comparison with 40 age-matched controls. They tested 29 cytokine levels in the plasma and reported overall lower levels of cytokines including chemokines associated with $\mathrm{T}$ cell immune activation [41].

- Another study tested plasma cytokine levels in 28 children with high functioning ASD in comparison with 28 age-matched controls. Authors reported elevated levels of plasma cytokines including IL-1 $\beta$, IL-1 receptor antagonist (IL1ra), IL-5, IL-8, IL-12p70, IL-13, IL-17, and CXCL1 (chemokine) [42].

- In other study, levels of soluble platelet endothelial cell adhesion molecule -1 (PECAM-1) and intercellular adhesion molecule-1 (ICAM-1) were studied, since PECAM-1 and ICAM-1 are impor- tant for $\mathrm{T}$ cell recruitment at the site of inflammation. In this study, authors reported higher levels of soluble PECAM-1 and ICAM1 in young ASD children $(N=49)$ as compared to agematched controls $(N=31)$ [43]. However, these adhesion molecules are not specific for $\mathrm{T}$ cell subsets and are expressed by other lineage cells.

These studies, which mainly focused on $\mathrm{T}$ cell immunity, have yielded conflicting results, and do not seem to indicate any underlying unifying immune abnormalities associated with T lineage cells. In addition, these results indicate the possibility of being skewed by the presence of high outliers. Reports of increased cytokine levels may indicate the presence of chronic inflammation that can lead to chronic $\mathrm{T}$ cell activation [44, 45]. It is possible that a portion of ASD children in these studies may have had chronic inflammation, thereby affecting levels of the above-described immune-parameters. Unfortunately, all of the studies described above lacked clinical characterization of the study subjects from the view of allergy/clinical immunology. It cannot be emphasized enough that behavioral/developmental assessments are not sufficient when assessing immune-parameters. Immunodeficiency and immune-dysregulation, as well as co-morbid conditions affecting immune functions, need to be assessed as routinely done in the field of clinical immunology.

Moreover, pain and discomfort caused by chronic infection and/or inflammation may have affected behavioral symptoms/cognitive activity in the above described studies, thereby skewing results. Behavioral changes associated with pain has been described in subjects with minimal expressive language [46]. We also observed fluctuations in behavioral symptoms in association of worsening pain and discomfort affected by co-morbid medical conditions in our clinic [15]. Additionally, the lack of longitudinal studies of these parameters makes it difficult to assess the clinical utility of these parameters.

\section{I-C Antigen presentation and HLA}

Adaptive immunity exerted by $\mathrm{T}$ and $\mathrm{B}$ cells is partly regulated by antigen (Ag) presenting cells (APC). Therefore, it may be speculated that various clinical features, such as frequent infection and adverse reactions to medications, can also be associated with impaired APC functions.

$\mathrm{Ag}$ presentation of APC has been partly dictated by human leukocyte antigens (HLA), human major histocompatibility complex (MHC). Therefore, mutations 
in the HLA region have long been suspected of having a role in ASD, as observed in many other autoimmune and neurodegenerative diseases. In addition to its role in the immune system, HLA also plays a role in the formation, refinement, maintenance, and plasticity of the brain [47].

Certain HLA types have been reported to be associated with ASD, which may differ among ethnic groups [17]. It appears that autism HLA associations have been observed across the entire HLA region both in classical and non-classical HLA genes [17]. Again this finding might be associated with the marked heterogeneity of ASD children as well polygenic natures of this condition. Recent study in 100 ASD children and 100 matched controls reported that HLA-DRB $1 * 03$ allele may have protective effects on ASD [48].

For future research, it may be rewarding to target ASD subjects with specific markers, such as a strong family history of autoimmunity, when assessing the association between HLA and autism. In fact, a high frequency of autoimmune diseases in families of ASD children has been reported by several researchers [in 3325 ASD subjects [49], in 420 ASD subjects [50], and 100 families with ASD children [51]].

As described above, there is substantial evidence of HLA association with autism. If this is the case, then one may wonder what evidence exists with regard to altered functions and/or phenotypes of APC in ASD children.

- Recently, in a study of 57 ASD children with 29 typically developing control children, the authors reported that the frequency of myeloid dendritic cells (MDCs) was increased in ASD children [52]. Authors reported a positive association between frequency of MDCs and amygdala volume/repetitive behaviors [52]. Authors also reported a positive association between frequency of plasmacytoid DCs (PDCs) and amygdale volume /developmental regression [52]. However, in this study, absolute numbers of MDCs and PDCs were not measured. Secondary to very low frequency of MDCs and PDCs in the peripheral blood (PB), absolute numbers of these MDC/PDC are considered to be more reliable. In our previous studies, we did not observe increase in absolute numbers of MDCs or PDCs in ASD children (unpublished observation), which is consistent with results of others in 23 autistic children vs. 23 controls [53].

Currently, we cannot say that there are specific markers associated with APC and HLA that aid in subgrouping ASD or assessing the disease outcome/treatment responses. However, HLA association with autism, as described above, may indicate susceptibility of a portion of ASD children to autoimmune conditions or chronic inflammation.

\section{Innate immunity}

Studies of immune-parameters in ASD children also included those associated with innate immunity. The results of studies focused on innate immune parameters are summarized in this section.

\section{II-A Complement system}

Complement cascade is an important effecter mechanism which operates in both adaptive and innate immunity. The presence of a high frequency of autoantibodies in ASD children and HLA association with autism has raised an interest in a possible role of complement system in ASD. This is partly due to the facts that complement activation by autoantibodies plays a role in antibody medicated autoimmune conditions, as observed in lupus, and that the chromosome locus of HLA and complement factors are located adjacently. Moreover, proteins associated with HLA and complement systems are also expressed in the CNS. As noted before, HLA proteins are known to play a role in the formation, refinement, maintenance, and plasticity of the brain as reviewed elsewhere [47]. Likewise, it is known that a complement cascade has a role during periods of active synapse elimination and is required for normal brain wiring, as reviewed elsewhere [54]. In these processes, resident innate cells in the CNS, such as microglial cells and astrocytes are found to be involved in synaptic elimination [54]. In that regard, aberrant expression or activation of HLA and complement systems in the brain can be associated with the development of ASD and may be reflected in peripheral markers associated with the complement system.

Several studies have shown altered parameters associated the complement system in ASD children, as summarized below:

- One study determined an association between complement (C) 4B null allele and autism in autistic children ( $N=80$, Age: $4-8$ years) as compared to age, ethnicity, and gender matched controls $(N=80)$. The frequency of the $\mathrm{C} 4 \mathrm{~B}$ null allele was higher in autistic children as compared to controls $(37.5 \%$ vs. $8.75 \%)$ and family history $(\mathrm{FH})$ of autoimmunity was associated with risk for autism (odds ratio $=6.26$ ) [55]. This is consistent with previous reports $[56,57]$. 
- High complement factor I activity was reported in the plasma of ASD children $(N=30$, Age 3-9 years) as compared with control children $(N=30$, age 3-12 years) [58].

- A proteomic study of serum proteins obtained from autistic children ( $N=69$, Age: $4-6$ years) revealed elevated levels of 4 serum proteins, apolipoprotein B-100, complement Factor H Related Protein (FHR1; a protein associated with complement degradation), complement factor $1 \mathrm{q}$ (C1q), and fibronectin 1 [59].

C4 deficiency is well known for its association with autoimmune diseases, such as atypical lupus, and given the complement system's role in normal synaptic wiring, the above described findings associated with the $\mathrm{C} 4 \mathrm{~B}$ null allele are not surprising. High complement factor I activity, C1q, and FHR1 can be associated with chronic inflammation. However, information regarding co-morbid conditions that could cause chronic inflammation and/or affect levels of the above described complement parameters are not described in the studies discussed above. In the proteomic study, the results obtained did not reveal changes in any of immuneparameters described in the Sections I and II, including inflammatory cytokines, in ASD children. This may be in partly due to differences in the methodologies utilized, the heterogeneity of the study subjects, and possible presence of various co-morbid conditions.

\section{II-B Effecter cell functions}

Abnormalities indicating effecter cell dysfunctions have been reported in ASD children. However, it must be noted, that functions of innate immune cells as effecter cells are also closely associated with adaptive immunity. Representative results focusing on innate immune abnormalities in ASD children are as follows:

\section{Natural killer (NK) cells}

- Expression of killer-cell immunoglobulin-like receptor (KIR) is important for NK cell functions, since KIR mediated NK cell activation is crucial for NK cells to eliminate precancerous cells, damaged cells, and cells infected with microbes. In studies of 158 Caucasian subjects with autism and 176 control subjects, authors reported higher transcript (mRNA) levels of 4 proteins associated with activation of KIR genes (2DSS, 3DS1, 2DS1, and 2DS4) as well as HLA-C2, a ligand to 2DS1 in peripheral blood cells from ASD children [60].
However, the increases in mRNA levels was relatively low $(<2.5$ fold) in this study.

- As previously indicated, in phenotypical analysis of PBMCs in ASD $(N=70)$ vs. control children $(N=35)$, increased frequency of NK cells was reported [36].

- ASD children $(N=52)$ were reported to have higher expression of $\mathrm{NK}$ cell receptors and effecter molecules including granzyme and perforin as compared to typically developing control children $(N=27)$ [61]. When NK cells are stimulated by NK target cells (K562 cells), authors also reported up-regulated protein expression of interfern- $\gamma($ IFN- $\gamma)$, perforin, and granzyme B in ASD children as compared to controls, while NK lytic activity was significantly reduced [61].

- Low NK lytic activity was also reported in autistic children ( $N=1027$, Age 2-15 yrs) as compared to 113 healthy controls, when K562 cells were used as target cells [62]. However, NK cell numbers were not inversely associated with NK cell cytotoxic activity [62]. Authors report that NK cell activity $<15 \mathrm{LU}$ ) was observed in autistic children and normal controls at $45 \%$ and $8 \%$, respectively [62].

These results are somewhat conflicting with the evidence indicating impaired NK lytic activity, despite reports of increased mRNA and protein expression of NK effecter molecules such as granzymes and perforin. Reduced NK lytic activity is often observed in chronic inflammation and the above-described findings might be explained by the presence of chronic inflammation in a portion of ASD subjects.

\section{Monocytes}

- Increased monocyte (Mo) numbers as well as increased plasma levels of neopterin, a marker of Mo activation, were reported in studies of ASD children $(N=31)$ as compared to age and gender matched normal controls $(N=28)$ [63].

- Increased fluorescence intensity of CD95 on $\mathrm{CD}_{14}{ }^{+}$Mo was reported in ASD children $(N=70)$ as compared to age-matched controls $(N=35)$ [36]. This finding may indicate chronic activation of Mo in a portion of ASD children. In this study, Mo numbers were not high in ASD children as opposed to the results reported by Sweeten et al.

- In studies of functions of purified PB Mo obtained from ASD children $(N=17)$ and control age-matched children $(N=16)$, authors reported 
increased production of inflammatory cytokines including IL-1ß, IL-6, IL-8, TNF- $\alpha$, CCL2 (chemokine for Mo), and GM-CSF in autistic children when cells were stimulated with agonists of toll like receptors (TLRs) 2 and 4 [64]. The results may indicate that a portion of ASD children has PB Mo producing high amounts of these cytokines. However, it is difficult to assess what clinical characteristics are associated with altered Mo functions, given the small number of study subjects. In this study, PB monocytes were positively sorted using a flow cytometer, which may cause the activation of Mo.

- In studies of transcription profiling of PB Mo, up-regulated gene expression of CCL2 and CCL7 (chemokines for Mo), in addition to other genes, were reported in ASD children clinically characterized with fluctuating behavioral symptoms and persistent GI symptoms $(N=19)$ as compared to ASD case controls $(N=28)$ and normal case control $(N=25)$. However, in those with fluctuating behavioral symptoms without GI symptoms $(N=14)$, such changes were not observed [8]. PBMCs obtained from the above described ASD children, with fluctuating behavioral symptoms and persistent GI symptoms, did not reveal increased production of inflammatory cytokines as compared to ASD and normal case controls [8]. This was not observed in ASD children without GI symptoms when tested using PBMCs, as well. The PB monocytes, in this study, were purified by negative selection using an immunoaffinity column.

- In a study of plasma chemokines from ASD children $(N=97)$ and age-matched typically developing controls $(N=87)$, levels of CCL2, a major chemokine for Mo, was reported to be higher in ASD children along with higher levels of CCL5 and CCL11 (chemokines) [39] than controls. Authors noted that higher levels of these plasma cytokines were positively associated with severity of impaired behaviors [39].

- In a study of 99 ASD children (5-10 years) and 40 age and gender matched unrelated controls, authors reported a decrease in plasma cytokines associated with chemotaxis of T cells, NK cells, and Mo [41].

In humans, PB Mo consists of 2 major subsets, classical or (M1) monocytes phenotypically identified as $\mathrm{CD}_{14}^{++}, \mathrm{CD}^{+} 6^{-}$cells, and alternatively activated or (M2) monocytes identified as $\mathrm{CD} 14^{+}, \mathrm{CD}_{16}{ }^{+}$ and $\mathrm{CD} 14^{\mathrm{dim}}{ }^{\mathrm{CD}} 16^{+}$cells [65]. M1 Mo express high levels of CXCR2, CCR1, and CCR2 (ligands to CCL2 and CCL7) [65]. Upon inflammatory stimuli, M1 Mo are recruited to the site of inflammation via chemokines (CCL2 and CCL7) sensed by their ligand, CCR2 [66]. M1 Mo recruited to the brain are thought to develop into bone marrow derived microglial (BMDM) cells [67]. Given the above findings, in a portion of ASD children, PB Mo may have a role in CNS inflammation, recruited into the CNS to become BMDM cells. In support of this assumption, up-regulated expression of CCL2 has been reported in microglial cells in autistic brains [68]. However, the results of these studies do not indicate universal activation of PB Mo in all ASD children. Instead, these results may indicate that only a portion of ASD children has activated Mo in peripheral circulation.

\section{Mast cells}

Mast cells are major effecter cells in IgE mediated Th2 responses. Many parents of ASD patients report 'allergic' symptoms in ASD children. Thus skewed Th2 responses associated with allergic disorders have been entertained in ASD children, as summarized in Section I. However, the results from studies examining $\mathrm{T}$ cell responses are conflicting as summarized in the Section I-b, and do not support generalized Th2 skewed responses in ASD. Instead, more recent studies indicated non-allergic mast cell activation in ASD children, triggered in a non-IgE mediated manner [69].

Mast cells play a role in both innate and adaptive immunity as effecter cells. In addition, mast cells reside in the brain and have a role in CNS inflammation triggered by stimuli not associated with $\operatorname{IgE}$ antibodies [69]. Therefore, some researchers have investigated markers associated with mast cell activation in ASD subjects.

- In a study of ASD children $(N=19)$ and agematched unrelated controls $(N=16)$, it was reported that neurotensin (NT), one of the markers of mast cell activation, was increased in the serum of ASD children as compared to controls [70].

- The subsequent study by the same group showed that NT induced release of extracellular mitochondrial DNA (mtDNA), which can be a target of auto-reactivity. Authors report higher levels of mtDNA in the serum of ASD children than controls, as well as presence of anti-mitochondrial antibody Type 2 in 14/20 ASD subjects [71]. 
On the basis of these results, authors indicated that a portion of ASD children may have increased activation of mast cells. However, the above described studies were conducted with a relatively small number of study subjects and it remains to be seen whether the data are reproducible. In addition, what specific clinical feature can be observed in ASD children who have mast cell 'hyperactivation' must be addressed. At this time, it is unclear how mast cell 'hyperactivation' is associated with ASD and the disease outcome.

\section{Chronic inflammation}

The studies examining immune abnormalities, as discussed thus far, do not indicate that specific immune lineage cells have a role in the onset and development of ASD. However, overall results appear to indicate the presence of chronic immune activation or inflammation in a portion of ASD children. Interestingly, chronic inflammation has also been implicated with other neuropsychiatric condition including schizophrenia [72, 73].

\section{III-A Chronic inflammation}

With regard to chronic inflammation, the existence of a genetic association with other chronic inflammatory conditions has been explored in both ASD and schizophrenia. In most of the chronic inflammatory conditions that have been addressed in schizophrenia, the risk of schizophrenia is implicated with gene-environmental factor interactions (epigenetic regulation). This may also be true for ASD as indicated in the following study:

- A study using genome-wide data sets obtained from ASD subject assessed the genetic association between autism and 6 autoimmune conditions. In this study the data were obtained from 941 multiplex families with autistic children [74]. The results indicate a link between autism and ankylosing spondylitis (AS) and multiple sclerosis (MS) [74]. Interestingly, authors found a negative association coefficient between MS and autism, but a positive coefficient between autism and AS [74]. These results indicate that a portion of ASD children may have certain components in common with some autoimmune conditions.

These results makes one wonder whether chronic inflammation and immune activation are truly observed in the brains of autistic subjects. Although studies of post-mortem brains from ASD individuals are limited, with only a small number of study subjects, recent studies indicate presence of immune mediated inflammation in the ASD brains:

- Recent transcription profiling of autistic brains (19 autistic brains and 17 control brains) revealed 2 major modules; a synaptic transmission module, which is strongly affected by genetic predisposition and suppressed in autism, and an immune activation module [75]. The immune module is up-regulated in autism and has little or no genetic association with the brain [75]. This finding indicates that immune dysfunction and subsequent inflammation of other organs may exert significant effects on the brain, in what can be referred to as 'immune or inflammatory autism'. However, no information is available regarding clinical phenotypes of these subjects, since brain tissues were obtained from tissue banks. In addition, authors reported no significant correlation between alleles reported to be associated with ASD in genomewide association study (GWAS) and mRNA levels of immune associated genes [75].

- In the study of immune transcriptomes in 6 autistic and 6 control brains, authors reported that expression profiles were more associated with the late recovery phase of autoimmune brain disorders than with the innate immune responses typically seen in neurodegenerative diseases [76].

- In another study, highly expressed ASD risk genes were investigated in developing brains by using previously published gene expression atlas (16 human brain regions) obtained from subjects with ages ranging from fetus to adult [77]. Interestingly, their results indicated that 219 previously described putative ASD risk genes may converge on cytokine signaling pathways involving $\mathrm{NF} \kappa \mathrm{B}$, Tnf, and Jnk [77]. This finding supports the assumption that immune signaling involved in inflammatory responses is associated with the risk of ASD, for at least some ASD subjects.

These transcriptome studies indicate that immune activation does not appear to be intrinsic to the CNS, and is more likely to be associated with activation of the immune system triggered by environmental factors and/or inflammatory processes associated with other organ systems. Also it should be noted, that such gene transcript profiles overlap those reported in patients with schizophrenia [73]. In these 2 conditions, prenatal activation of the immune system has been implicated. However, the above described gene expression studies, using postmortem human brains, are limited to a small numbers of study subjects and 
lack information of clinical features and other comorbid conditions. In addition, how such information can be translated into peripheral biomarkers remains unanswered.

Peripheral biomarkers of immune activation in ASD have been studied, as summarized previously in the sections I and II. Although numbers of study subjects are much larger than brain tissue studies, results are somewhat contradictory, partly reflecting the heterogeneity of the ASD study subjects, as has been discussed. This may also be the case in patients with schizophrenia. However, recent metaanalysis indicated increased levels of IL-1B, IL-6, and transforming growth factor- $\beta$ (TGF- $\beta$ ) during acute episodes of schizophrenia [78]. Other studies also indicate changes in inflammatory cytokines in peripheral blood during acute phases of schizophrenia [73].

As for ASD children, peripheral immune activation appears to be observed in only a portion of ASD children and may be associated with both the severity of ASD symptoms and the degree of impairment in cognitive activity, as summarized in previous sections. Based on the currently available research results, it may be reasonable to state that at least a portion of ASD children exhibit immune activation or dysregulation in the brain, which may be detected in the PB at the time of acute flare ups of their underlying inflammatory condition (s).

\section{III-B Early immune activation}

The effects of early inflammation were initially postulated from epidemiological studies indicating an increased risk of ASD with prenatal exposure to various viruses [79] and maternal history of autoimmune diseases $[49,80]$. As summarized in the previous sections, the presence of antibodies against fetal brains in mothers during pregnancy and after birth may be indicative of possible immune activation in the fetal brain. Likewise, post-natal immune activation (such as infection) in early life was also postulated to affect human brain development, which is supported by findings in animal models.

In maternal infection/inflammation models or socalled MIA models, various inflammatory stimuli and microbial agents were used during pregnancy and the results indicated altered levels of inflammatory cytokines in the fetal and neonatal brains in parallel to long-term effects on the offspring's behaviors, as reviewed in elsewhere [79]. The effects of MIA on behaviors reported in representative recent studies in rodent models are as follows:
- MIA caused by poly (I:C) (synthetic doublestranded RNA) in pregnant 57BL/6J mice, led to increased IL- 6 expression at mRNA and protein levels in the placenta in parallel to increased frequency of $\mathrm{CD}^{+} 9^{+}$decidual macrophages, granulocytes, and NK cells [81]. Authors also report IL-6 dependent disruption of growth hormone (GH)-insulin like growth factor (IGF) axis with decreased GH, IGF1, and IGF binding protein 3 (IGFBP3) levels, which likely alters fetal development [81].

- In 57BL/6J mice, MIA by poly (I:C) at gestational day (GD) 16 was reported to induce higher levels of IL-13, IL-7, IL-13, CCL2, CXCL10, CCL3, VEGF (vascular endothelial growth factor) in the fetal brain [82].

- A single maternal injection of IL-6 on GD12.5 in mice was reported to have resulted in deficits in prepulse inhibition (PPI) and latent inhibition (LI) in the adult offsprings [83]. The authors also reported preventive effects of anti-IL-6 antibody on PPI, LI, and exploratory/social deficits induced by MIA by poly (I:C) [83]. This finding may indicate that IL-6 is a key mediator of neurodevelopmental changes caused by MIA in this model.

- MIA induced by injection of poly (I:C) at GD $10.5,12.5$, and 14.5 in mice was reported to induce communication differences in early life, as well as in adult life [84]. In addition, MIA adult offspring exhibited increased repetitive and stereotyped behaviors and decreased sociability [84]. Repeated MIA in this murine model appeared to have produced all the core features of ASD.

- One study has shown that behavioral and immunological effects of MIA in murine models are strain-dependent [85]. In this study, MIA induced by poly (I:C), resulted in behavioral changes in BTBR $\mathrm{T}^{+} \mathrm{tf} / \mathrm{J}$ mice but not in C57BL/6J mice. This study indicates the importance of genetic components in the development of ASD symptoms in MIA murine models.

In animal models of MIA, it was also shown that MIA affects neuronal and immune system development. Representative results of recent studies are summarized below:

- In a murine MIA model induced by poly (I:C), authors reported significantly decreased gene expression of Pax6, a master regulator of transcription factors in cortical progenitors and altered 
laminar allocation, in the daughter neurons, along with impaired development of the upper layer of the brain cortex $[86,87]$.

- In a monkey model of prenatal endotoxiemia in whom LPS was given for 2 consecutive days 6 weeks prior to term delivery, it was found that global white matter volume of brain has increased $8.8 \%$ in the offspring at 1 year of age when assessed by magnetic resonance imaging (MRI) [88]. This finding was also paralleled with selective changes in regional gray matter volume and cortical thickness of the offspring brains [88].

- In a rat model of MIA caused by lipopolysaccharide (LPS; $100 \mu \mathrm{g} / \mathrm{kg}$ ) at GD 15/16, authors reported decreased expression of D1 and D2 dopamine receptors (D1R, D2R), and dopamine transporter binding levels in the medial prefrontal cortex at 35 and 60 days of age, as compared to controls [89]. Authors also reported decrease of $\mathrm{D}_{2} \mathrm{R}^{+}$neurons in the infalimbic/prelimbic part of medial prefrontal cortex in this model [89].

- In a similar rat MIA model induced by LPS $(250 \mu \mathrm{g} / \mathrm{kg})$ on GD15, offspring born to LPStreated dams exhibited reduced social preference and exploration behaviors as juveniles and young adult rats [90]. At $4 \mathrm{~h}$ post maternal LPS injection, microarray analysis of the fetal brain revealed reduced expression of developmentally-regulated and brain-specific genes that regulate neuronal migration of GABAergic interneurons, indicating the effects on cerebral cortex development [90].

- In a murine MIA model with poly (I:C) $(20 \mathrm{mg} / \mathrm{kg})$ given on GD12.5, persistent immunodysregulation in offspring was reported including decreased frequency of Foxp ${ }^{+} \mathrm{CD} 25^{+}$ regulatory $\mathrm{T}$ (Treg) cells, increased production of IL- 6 and IL-17 by isolated CD4 ${ }^{+} \mathrm{T}$ cells in response to phorbol 12-myristate 13-acetate (PMA)/ionomycin, and increased frequency of peripheral Gr-1 ${ }^{+}$cells (Gr-1; marker of granulocytes) [91]. Transfer of hematopoietic stem cells (HSC) from these MIA offspring did not reproduce this phenotype in the recipient mice. However, these MIA offspring mice lost their stereotyped/repetitive and anxiety-like behaviors following HSC transplantation from both healthy and MIA mice after irradiation [91]. This may indicate that environmental programming can result in alternation of the immune system.

As described above, the animal models of MIA indicate lasting effects on neuronal development, social behaviors, and immune dysregulation on offspring of MIA dams. However, as indicated above, one study reported that MIA effects can be straindependent [85], pointing out the importance of genetic predisposition. These results still leave us with a question as to whether peri-natal infection in humans is associated with ASD risk. Results of epidemiological studies relating to MIA in humans do not provide convincing evidence to support a critical role of peri-natal infection in development of ASD:

- In autism subjects $(N=403)$ born between 1995 to 1999, frequency of infection diagnoses in the 1st 2 years of life were slightly less in ASD children than controls $(N=2100)(95 \%$ vs. $97.5 \%)$ but the frequency of having an infection in the first 30 days of life was reported to be slightly higher in children with autism than in controls (22.6\% vs. $18.7 \%$ ) [92].

- A population-based cohort study in Denmark ( $N=96736,8-14$ years, ASD children: $N=976)$ targeting children born from 1997 to 2003, evaluated the association between autism diagnosis and infection, febrile episodes, and antibiotic use on the basis of self-report by mothers during pregnancy and early postpartum. Results did not support an association between mild infections, febrile episodes, or use of antibiotics during pregnancy and a diagnosis of ASD/infantile autism [93]. Maternal influenza infection was reported to be associated with a twofold increased risk of infantile autism and prolonged episodes of fever were associated with a threefold increased risk of infantile autism, but authors cautioned that these might be chance findings [93].

- In the same Danish cohort population described above ( $N=92,583$, ASD children: 945$)$, investigators also reported no general association between maternal reports of infectious illness (from birth to $19 \mathrm{mo}$ ) and ASD [93]. However, authors reported that hospital contact for all causes was associated with an increased risk for ASD diagnosis [93]; the reason of this finding is unclear.

- Utilizing neonatal dried blood samples retrieved from The Danish Newborn Screening Biobank of Children, authors studied cytokine levels in neonatal blood in children that were later diagnosed with ASD $(N=359)$ and in control subjects $(N=741)$. The results revealed decreased levels of IFN- $\gamma$, IL-2, IL-4, and IL-6 in ASD subjects [94]. Authors attributed this to a depressed immune 
cell activity during the neonatal period in ASD children [94].

As summarized above, despite accumulating results supporting a role of MIA in animal models, translating these results to humans appears challenging. This is partly due to the marked heterogeneity of genetic and environmental factors of ASD subjects. As promoted by others, better clinical characterization and subgrouping of ASD subjects on the basis of reliable objective biomarkers other than behavioral symptoms, may be the first step toward elucidating a role of inflammation or MIA in ASD. However, objective biomarkers for ASD and/or ASD subsets are not yet established at this time. Therefore, subgrouping ASD subjects on the basis of clinically significant co-morbid conditions may be a viable alternative. An example of such a marker to aid in subgrouping is GI symptoms, which are frequently observed in ASD children at high frequency [4]. In the next section, GI inflammation reported in ASD subjects will be discussed.

\section{III-C Chronic inflammation in the gut}

Interaction between the gut microbiota and the gut mucosal immune system has significant effects on gut immune homeostasis and oral tolerance [95]. Impaired interactions between microbiota and the gut immune system are implicated with various chronic inflammatory conditions including inflammatory bowel disease and food allergy (FA) [95]. Interestingly, retrospective review of early medical histories of 99 ASD children revealed higher frequency of ear infection and more frequent antibiosis as compared to 24 control children [96]. Similarly, a high frequency of ear infection ( $>8 x$ in the $1^{\text {st }} 3$ yrs of life) has also been reported in ASD children (51 ASD children vs. 40 control children [97], as well as higher frequency of antibiosis during 12 months of life (15 ASD children vs. 11 controls) [98] and during the first 18 months of life (78 ASD children vs. 31 controls) [99]. These results indicate that frequent antibiosis and resultant dysbiosis may be one of the predisposing factors for GI inflammation in ASD children.

There are bidirectional connections between the GI tract including gut microbiota and the CNS via the enteric nervous system [100, 101]. In animal models, gut infection with pathogenic bacteria has been reported to induce behavioral changes [102-104]. Given the fact that ASD children exhibit a high frequency of GI symptoms, as reviewed elsewhere [4], chronic gut inflammation identified as persistent GI symptoms, may be a marker for ASD chil- dren with chronic immune activation. Several studies have been conducted to address the pathogenesis of chronic GI symptoms observed in ASD children. Some selected studies, including those addressing interactions between the gut immune system and gut microbiota in ASD children are summarized below:

- In studies of 58 ASD children (Age 2.5-18 years), GI symptoms assessed by 6-item GI Severity Index (6-GSI) were positively associated with autism severity assessed by the Autism Treatment Evaluation Checklist (ATEC) [105]. In this study, authors reported lower levels of Bifidobacter and higher levels of Lactobacillus in ASD stools as compared to 39 typically growing children [105].

- In 199 ASD subjects with substantial GI symptoms warranting endoscopic examination, duodenal biopsy tissues were evaluated for intestinal disaccharidase activity. In this study, authors report that the presence of intestinal inflammation was found only in $6 \%$ of ASD subjects and lactase deficiency was not associated with intestinal inflammation or injury [106]. Inflammation could be found in a lower gut where it is expected to have a higher bacterial density.

- Ileal intestinal biopsies obtained from ASD children $(N=15)$ and non-ASD children with GI condition $(N=7)$ showed dysbiosis in ASD children with decreases in Bacteroidetes, increases in the ratio of Firmicutes to Bacteroidetes, and increases in Betaproteobacteria [107]. These changes in the microbiome were reported to be associated with changes in expression of disaccharidases and transporters [107].

- Propionic acid (PPA), a short chain fatty acid (SCFA) and a metabolic end-product of enteric bacteria in the gut, has been reported to affect behavioral symptoms. In studies of male rats, MacFabe et al. reported that PPA administered intra-cerebro-ventricularly resulted in restricted behavioral interest to a specific object, impaired social behavior, and impaired reversal in a T-maze task as compared to control rats [108]. It should be noted that SCFA has been noted to have profound immunomodulating effects on gut mucosal immune system [95].

- The same group also reported that intraperitoneal injection of PPA in rats induced significant place avoidance and reduced locomotive activity on acquisition trials [109].

- In rats orally treated with a neurotoxic dose of buffered PPA, brain homogenates revealed 
an increase in oxidative stress markers and a decrease in glutathione (GSH), glutathione peroxidase (GPX), and catalase activities [110]. Increased levels of IL- 6 , TNF- $\alpha$, IFN- $\gamma$, and heat shock protein 70 (HSP70) were also detected in the brain homogenates, as compared to control rats treated with PBS (vehicle only) [110].

- In ASD children with GI symptoms $(N=18)$ and typically developing children without GI inflammation or with Crohn's disease $(N=27$ total), it was reported that in both peripheral blood and gut mucosa, $\mathrm{CD}^{+}{ }^{\mathrm{TNF}-} \alpha^{+}$and $\mathrm{CD} 3^{+} \mathrm{IFN}-\gamma^{+} \mathrm{T}$ cells were higher in ASD children than in controls without gut inflammation, while $\mathrm{CD} 3^{+} \mathrm{IL}-10^{+} \mathrm{T}$ cells were lower in ASD children with GI symptoms [111]. Authors also reported increased mucosal $\mathrm{CD}^{+} \mathrm{IL}_{-} 4^{+} \mathrm{T}$ cells in ASD children [111].

- In 21 ASD subjects with GI symptoms and 65 developmentally normal controls, of which 38 had histological evidence of gut inflammation, changes of cytokine profiles of mucosal lymphocytes in duodenal and colonic biopsies were studied. Authors reported increased frequency of $\mathrm{CD}^{+}{ }^{+} \mathrm{TNF}-\alpha^{+}, \mathrm{CD}^{+}{ }^{+} \mathrm{IFN}-\gamma^{+}$cells but decreased $\mathrm{CD}^{+} \mathrm{IL}-10^{+}$cells in mucosal specimen from ASD subjects [112].

Studies of animal models support the effects of gut microbiomes, as described above. Previous studies of ASD subjects with GI symptoms also indicate evidence of immune activation in the gut and its effects on behavioral symptoms, although these studies were done with relatively small numbers of ASD subjects. Even so, questions remain. Can chronic gut inflammation be reflected in abnormalities in immune-parameters that can be detected in the PB and what are the causes of the GI symptoms frequently observed in ASD children? The etiology of GI symptoms is still controversial (Buie et al., 2010) and no consensus currently exists. Nevertheless, as indicated above, dysbiosis may have a role.

In our previous studies, we have evaluated GI symptoms in ASD children with regard to FA. There is no evidence of increased IgE mediated FA associated with Th2 skewed responses in our studies (Jyonouchi et al., 2005, 2008, 2010). However, our previous studies revealed a high frequency of delayed type FA (NFA) in young ASD children (2-6 years) $(N=109)$ [113]. Our previous results also indicated a high frequency of under-diagnosis and under-treatment of NFA in ASD children, which may be partly attributed to their lim- ited expressive language, since NFA diagnosis is solely based on clinical manifestation at this time [114, 115]. Then, if our results are valid, why is NFA so frequently seen in ASD children? It may be that this is a reflection of underlying immunodysregulation. If this is the case, the evidence of NFA may be another marker for subgrouping ASD children. Further studies will be needed with better characterization of ASD subjects, ideally in a prospective, longitudinal study.

\section{III-D Subgrouping of ASD children}

Biomarkers: Currently, there are no standardized biomarkers to identify autism or specific subgroups of autism in the absence of known gene mutations. Additionally, the biomarkers that would provide the most benefit and are in dire need are those helpful in assessing the risk of autism, disease outcomes, and responses to treatment measures. Accumulation of autism risk factors by genetic studies may enable us to assess the risk of autism as an early screening measure. Identified immune abnormalities may also be able to serve as markers, provided phenotypical correlation is firmly established. For example, in a community-based, prospective, longitudinal study using PBMCs, Glatt et al. identified abnormalities of mRNA expression associated with ASD in 50\% of 60 infants who were considered to be at risk for ASD, in comparison of 68 normal controls, 17 at risk for global developmental delay, and 34 at risk for language delay [116]. Refined biomarkers will be helpful in the early detection and possibly subgrouping ASD children.

Inflammatory autism: In a study of transcriptomes in autistic brain, results indicated the presence of 'inflammatory autism' [75]. In line with this concept, we have previously reported the existence of a group of ASD children characterized by fluctuating behavioral symptoms triggered by immune insults, such as microbial infection, along with clinical features indicating immunodysregulation such as frequent respiratory infection, adverse reaction to medications, and persistent GI symptoms. In these subjects $(N=19)$, we reported up-regulated mRNA levels of certain inflammatory parameters including CCL2 and CCL7 in PB Mo purified by negative selection as compared to those obtained from normal $(N=26)$ and ASD case controls $(N=28)$ [8]. Paradoxically, in these subjects, decreased production of inflammatory cytokines, including IL-6 and IL-1 $\beta$ by PBMCs was found. This resembles a chronic inflammation condition in the absence of an acute flare up. Further analysis of functions of PB Mo in these subjects, categorized as ASD-inflammatory 

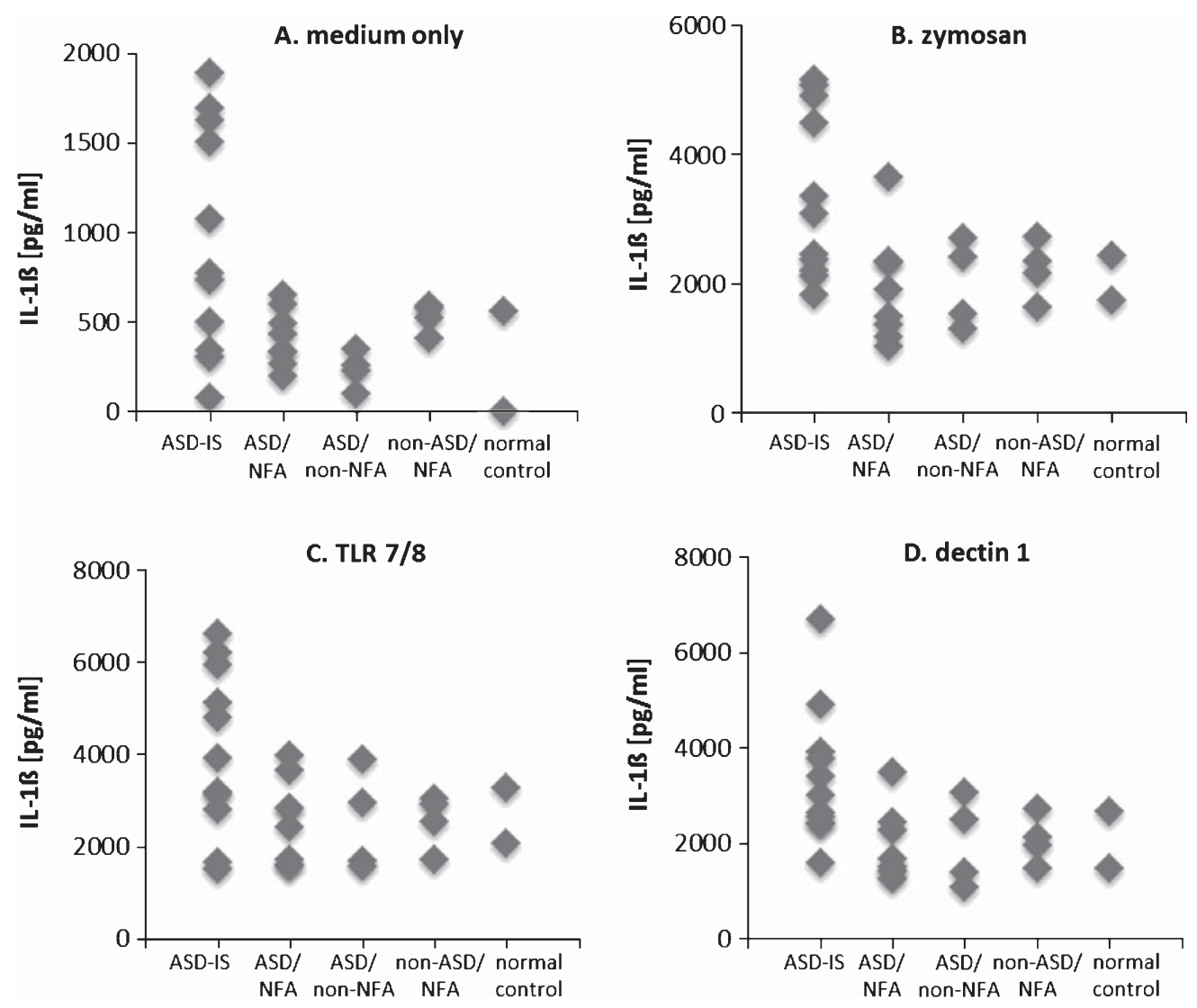

Fig. 1. IL-1 $\beta$ production by purified PB Mo from ASD-IS children as compared to ASD controls with or without NFA (ASD/NFA and ASD/nonNFA) and non-ASD controls with or without NFA (non-ASD/NFA and normal control). In these assays, PB samples were obtained when NFA was under control after implementation of the restricted diet. PB Mo was isolated negatively from PBMCs using immunoaffinity column. Then PB Mo $\left(0.25 \times 10^{6}\right.$ cells $\left./ \mathrm{ml}\right)$ were incubated overnight in the absence of stimulant (medium only) (Panel A) or with agonists of TLR2/6 (zymosan; Panel B), TLR7/8 (Panel C), or dectin-1 agonist (Panel D) and levels of IL-1 $\beta$ in the culture supernatants were measured. Each data point represents datum obtained from each study subject. Results are preliminary but indicated higher levels of IL-1ß production in ASD-IS subjects as compared to both ASD and non-ASD controls. History of NFA did not appear to contribute to increased IL-1ß production irrespective of ASD diagnosis.

subtype in (ASD-IS) in our study, indicates a persistent activated state of PB Mo (Fig. 1). Contradictory results of suppressed inflammatory cytokine production when PBMCs were used may be associated with the suppressive actions of the other lineage cells such as Treg cells in the absence of an acute flare up. However, such counter-regulatory mechanisms may be easily broken during acute flare ups with immune activation.

Examination of immune functions or immuneparameters in such ASD subjects (ASD-IS children in our study) during and out of flare ups may be beneficial if these immune parameters are studied in comparison with results of behavioral and developmental assessment. It is our experience, that in ASD-IS subjects, behavioral assessment results are impacted significantly by their diseases status - worsening behavioral symptoms are typically observed in the 'flare up' state (unpublished observation).

Summary statement: In this review, the current state of research examining immune abnormalities in ASD children is summarized. A wide range of immune abnormalities have been reported in ASD children, involving almost all arms the immune system. To date, these results do not indicate that there are immune defects common to all ASD children or that there are unifying immune defects that affect a specific pathway(s) or specific immune lineage cells in ASD. Instead result of these studies may indicate the presence of chronic inflammation, in a portion of ASD children. Causes of chronic inflammation are likely multi-factorial affected by both genetic and environmental factors. However, the effects of MIA and maternal autoantibodies may have a role in a portion of 
ASD children, although phenotypical characterization of ASD children with 'chronic inflammation' is lacking. Presence of chronic inflammation may affect both behavioral symptoms and cognitive activity.

As emphasized repeatedly in this review, when assessing utility of immunoparameters in ASD children, characterization of clinical phenotypes from the view of allergy/immunology will be crucial, in addition to behavioral/developmental assessments. Unfortunately, in most immune studies of ASD children, such evaluation is lacking. In addition, it is difficult to assess a role of immunoparameters, if reproducibility of the results and or changes of these parameters in association with changes in clinical features, such as behavioral symptoms, are not addressed carefully. In addition, the effects of co-morbid conditions that can affect both the results of immunoparameters as well as behavioral symptoms, via pain and discomfort also need to be carefully addressed.

It will be a daunting task to evaluate all these components. However, this may be done as a longitudinal prospective study focusing on ASD children with specific clinical features such as GI symptoms or FA, in comparison with ASD and normal case controls.

\section{ACKNOWLEDGMENTS}

This study was partly funded by Jonty Foundation, St. Paul, MN and ARI, San Diego, CA. The author is thankful for Dr. L. Huguenin for critically reviewing this manuscript.

\section{CONFLICT OF INTEREST STATEMENT}

The author has nothing to declare.

\section{REFERENCES}

[1] Abrahams BS, Geschwind DH. Advances in autism genetics: On the threshold of a new neurobiology. Nat Rev Genet. 2008; 9(5): 341-355.

[2] Rudan I. New technologies provide insights into genetic basis of psychiatric disorders and explain their co-morbidity. Psychiatr Danub. 2010; 22(2): 190-192.

[3] Betancur C. Etiological heterogeneity in autism spectrum disorders: More than 100 genetic and genomic disorders and still counting. Brain Res. 2011; 1380: 42-77.

[4] Buie T, Campbell DB, Fuchs GJ, 3rd, Furuta GT, Levy J, Vandewater J. et al. Evaluation, diagnosis, and treatment of gastrointestinal disorders in individuals with ASDs: A consensus report. Pediatrics. 2010; 125(Suppl 1): S1-S18.

[5] Nikolov RN, Bearss KE, Lettinga J, Erickson C, Rodowski M, Aman MG. et al. Gastrointestinal symptoms in a sample of children with pervasive developmental disorders. J Autism Dev Disord. 2009; 39(3): 405-413.
[6] Brown AC, Mehl-Madrona L. Autoimmune and gastrointestinal dysfunctions: Does a subset of children with autism reveal a broader connection? Expert Rev Gastroenterol Hepatol. 2011; 5(4): 465-477.

[7] Jyonouchi H, Geng L, Cushing-Ruby A, Quraishi H. Impact of innate immunity in a subset of children with autism spectrum disorders: A case control study. J Neuroinflammation. 2008; 5: 52 .

[8] Jyonouchi H, Geng L, Streck DL, Toruner GA. Children with autism spectrum disorders (ASD) who exhibit chronic gastrointestinal (GI) symptoms and marked fluctuation of behavioral symptoms exhibit distinct innate immune abnormalities and transcriptional profiles of peripheral blood (PB) monocytes. J Neuroimmunol. 2011; 238(1-2): 73-80.

[9] Heuer L, Ashwood P, Schauer J, Goines P, Krakowiak P, Hertz-Picciotto I. et al. Reduced levels of immunoglobulin in children with autism correlates with behavioral symptoms. Autism Res. 2008; 1(5): 275-283.

[10] Heuer LS, Rose M, Ashwood P, Van de Water J. Decreased levels of total immunoglobulin in children with autism are not a result of B cell dysfunction. J Neuroimmunol. 2012; 251(1-2): 94-102.

[11] Grether JK, Croen LA, Anderson MC, Nelson KB, Yolken RH. Neonatally measured immunoglobulins and risk of autism. Autism Res. 2010; 3(6): 323-332.

[12] Wasilewska J, Kaczmarski M, Stasiak-Barmuta A, Tobolczyk J, Kowalewska E. Low serum IgA and increased expression of CD23 on B lymphocytes in peripheral blood in children with regressive autism aged 3-6 years old. Arch Med Sci. 2012; 8(2): 324-331.

[13] Croonenberghs J, Wauters A, Devreese K, Verkerk R, Scharpe S, Bosmans E. et al. Increased serum albumin, gamma globulin, immunoglobulin IgG, and IgG2 and IgG4 in autism. Psychol Med. 2002; 32(8): 1457-1463.

[14] Wei H, Malik M, Sheikh AM, Merz G, Ted Brown W, Li $\mathrm{X}$. Abnormal cell properties and down-regulated FAK-Src complex signaling in B lymphoblasts of autistic subjects. Am J Pathol. 2011; 179(1): 66-74.

[15] Jyonouchi H. Autism spectrum disorders and allergy: Observation from a pediatric allergy/immunology clinic. Expert Rev Clin Immunol. 2010; 6(3): 397-411.

[16] Jyonouchi H, Geng L, Streck DL, Toruner GA. Immunological characterization and transcription profiling of peripheral blood (PB) monocytes in children with autism spectrum disorders (ASD) and specific polysaccharide antibody deficiency (SPAD): case study. J Neuroinflammation. 2012; 9: 4.

[17] Torres AR, Westover JB, Rosenspire AJ. HLA Immune Function Genes in Autism. Autism Res Treat. 2012; 2012: 959073.

[18] Singh VK, Warren RP, Odell JD, Warren WL, Cole P. Antibodies to myelin basic protein in children with autistic behavior. Brain Behav Immun. 1993; 7(1): 97-103.

[19] Bashina VM, Kozlova IA, Kliushnik TP, Simashkova NV, Danilovskaia EV, Gorbachevskaia NL. et al. An elevation in the level of autoantibodies to nerve-growth factor in the blood serum of schizophrenic children. Zh Nevrol Psikhiatr Im S S Korsakova. 1997; 97(1): 47-51.

[20] Connolly AM, Chez MG, Pestronk A, Arnold ST, Mehta S, Deuel RK. Serum autoantibodies to brain in LandauKleffner variant, autism, and other neurologic disorders. J Pediatr. 1999; 134(5): 607-613.

[21] Rosenspire A, Yoo W, Menard S, Torres AR. Autism spectrum disorders are associated with an elevated autoantibody 
response to tissue transglutaminase-2. Autism Res. 2011; 4(4): 242-249.

[22] Cabanlit M, Wills S, Goines P, Ashwood P, Van de Water J. Brain-specific autoantibodies in the plasma of subjects with autistic spectrum disorder. Ann N Y Acad Sci. 2007; 1107 : 92-103.

[23] Goines P, Haapanen L, Boyce R, Duncanson P, Braunschweig D, Delwiche L. et al. Autoantibodies to cerebellum in children with autism associate with behavior. Brain Behav Immun. 2011; 25(3): 514-523.

[24] Wills S, Rossi CC, Bennett J, Martinez Cerdeno V, Ashwood P, Amaral DG. et al. Further characterization of autoantibodies to GABAergic neurons in the central nervous system produced by a subset of children with autism. Mol Autism. 2011; 2: 5 .

[25] Al-Ayadhi LY, Mostafa GA. A lack of association between elevated serum levels of S100B protein and autoimmunity in autistic children. J Neuroinflammation. 2012; 9: 54.

[26] Singer HS, Morris CM, Gause CD, Gillin PK, Crawford $\mathrm{S}$, Zimmerman AW. Antibodies against fetal brain in sera of mothers with autistic children. J Neuroimmunol. 2008; 194(1-2): 165-172.

[27] Croen LA, Braunschweig D, Haapanen L, Yoshida CK, Fireman B, Grether JK, et al. Maternal mid-pregnancy autoantibodies to fetal brain protein: The early markers for autism study. Biol Psychiatry. 2008; 64(7): 583588.

[28] Heuer L, Braunschweig D, Ashwood P, Van de Water J, Campbell DB. Association of a MET genetic variant with autism-associated maternal autoantibodies to fetal brain proteins and cytokine expression. Transl Psychiatry. 2011; 1: e48.

[29] Braunschweig D, Duncanson P, Boyce R, Hansen R, Ashwood P, Pessah IN. et al. Behavioral correlates of maternal antibody status among children with autism. J Autism Dev Disord. 2012; 42(7): 1435-1445.

[30] Braunschweig D, Golub MS, Koenig CM, Qi L, Pessah IN Van de Water J. et al. Maternal autism-associated IgG antibodies delay development and produce anxiety in a mouse gestational transfer model. J Neuroimmunol. 2012; 252(12): 56-65.

[31] Bauman MD, Iosif AM, Ashwood P, Braunschweig D, Lee A, Schumann CM, et al. Maternal antibodies from mothers of children with autism alter brain growth and social behavior development in the rhesus monkey. Transl Psychiatry. 2013; 3: e278.

[32] Nordahl CW, Braunschweig D, Iosif AM, Lee A, Rogers S, Ashwood P, et al. Maternal autoantibodies are associated with abnormal brain enlargement in a subgroup of children with autism spectrum disorder. Brain Behav Immun. 2013.

[33] Braunschweig D, Krakowiak P, Duncanson P, Boyce R, Hansen RL, Ashwood P. et al. Autism-specific maternal autoantibodies recognize critical proteins in developing brain. Transl Psychiatry. 2013; 3: e277.

[34] Gupta S, Aggarwal S, Rashanravan B, Lee T. Th1- and Th2-like cytokines in $\mathrm{CD}^{+}$and $\mathrm{CD} 8^{+} \mathrm{T}$ cells in autism. J Neuroimmunol. 1998; 85(1): 106-109.

[35] Singh VK. Plasma increase of interleukin-12 and interferongamma. Pathological significance in autism. J Neuroimmunol. 1996; 66(1-2): 143-145.

[36] Ashwood P, Corbett BA, Kantor A, Schulman H, Van de Water J, Amaral DG. In search of cellular immunophenotypes in the blood of children with autism. PLoS ONE. 2011; 6(5): e19299.
[37] Ashwood P, Krakowiak P, Hertz-Picciotto I, Hansen R, Pessah IN, Van de Water J. Altered T cell responses in children with autism. Brain Behav Immun. 2011; 25(5): 840-849.

[38] Sykes L, MacIntyre DA, Yap XJ, Teoh TG, Bennett PR. The Th1:th2 dichotomy of pregnancy and preterm labour. Mediators Inflamm. 2012; 2012: 967629.

[39] Ashwood P, Krakowiak P, Hertz-Picciotto I, Hansen R, Pessah I, Van de Water J. Elevated plasma cytokines in autism spectrum disorders provide evidence of immune dysfunction and are associated with impaired behavioral outcome. Brain Behav Immun. 2011; 25(1): 40-45.

[40] Weaver CT, Elson CO, Fouser LA, Kolls JK. The Th17 pathway and inflammatory diseases of the intestines, lungs, and skin. Annu Rev Pathol. 2013; 8: 477-512.

[41] Manzardo AM, Henkhaus R, Dhillon S, Butler MG. Plasma cytokine levels in children with autistic disorder and unrelated siblings. Int J Dev Neurosci. 2012; 30(2): 121127.

[42] Suzuki K, Matsuzaki H, Iwata K, Kameno Y, Shimmura C, Kawai S. et al. Plasma cytokine profiles in subjects with high-functioning autism spectrum disorders. PLOS ONE. 2011; 6(5): e20470.

[43] Onore CE, Nordahl CW, Young GS, Van de Water JA, Rogers SJ, Ashwood P. Levels of soluble platelet endothelial cell adhesion molecule-1 and P-selectin are decreased in children with autism spectrum disorder. Biol Psychiatry. 2012; 72(12): 1020-1025.

[44] Fornasa G, Groyer E, Clement M, Dimitrov J, Compain C, Gaston AT. et al. TCR stimulation drives cleavage and shedding of the ITIM receptor CD31. J Immunol. 2010; 184(10): 5485-5492.

[45] Ohnishi A, Miyake Y, Matsushita H, Matsumoto K, Takaki A, Yasunaka T. et al. Serum levels of soluble adhesion molecules as prognostic factors for acute liver failure. Digestion. 2012; 86(2): 122-128.

[46] Carr EG, Owen-Deschryver JS. Physical illness, pain, and problem behavior in minimally verbal people with developmental disabilities. J Autism Dev Disord. 2007; 37(3): $413-424$.

[47] Needleman LA, McAllister AK. The major histocompatibility complex and autism spectrum disorder. Dev Neurobiol. 2012; 72(10): 1288-1301

[48] Mostafa GA, Shehab AA, Al-Ayadhi LY. The link between some alleles on human leukocyte antigen system and autism in children. J Neuroimmunol. 2013; 255(1-2): 70-74.

[49] Atladottir HO, Pedersen MG, Thorsen P, Mortensen PB, Deleuran B, Eaton WW. et al. Association of family history of autoimmune diseases and autism spectrum disorders. Pediatrics. 2009; 124(2): 687-694.

[50] Croen LA, Grether JK, Yoshida CK, Odouli R, Van de Water J. Maternal autoimmune diseases, asthma and allergies, and childhood autism spectrum disorders: A case-control study. Arch Pediatr Adolesc Med. 2005; 159(2): 151-157.

[51] Sweeten TL, Bowyer SL, Posey DJ, Halberstadt GM, McDougle CJ. Increased prevalence of familial autoimmunity in probands with pervasive developmental disorders. Pediatrics. 2003; 112(5): e420

[52] Breece E, Paciotti B, Nordahl CW, Ozonoff S, Van de Water JA, Rogers SJ. et al. Myeloid dendritic cells frequencies are increased in children with autism spectrum disorder and associated with amygdala volume and repetitive behaviors. Brain Behav Immun. 2012.

[53] Gupta S, Samra D, Agrawal S. Adaptive and Innate Immune Responses in Autism: Rationale for Therapeutic Use of Intravenous Immunoglobulin. J Clin Immunol. 2010. 
[54] Stephan AH, Barres BA, Stevens B. The complement system: An unexpected role in synaptic pruning during development and disease. Annu Rev Neurosci. 2012; 35: 369-389.

[55] Mostafa GA, Shehab AA. The link of C4B null allele to autism and to a family history of autoimmunity in Egyptian autistic children. J Neuroimmunol. 2010; 223(1-2): 115119.

[56] Warren RP, Singh VK, Averett RE, Odell JD, Maciulis A, Burger RA. et al. Immunogenetic studies in autism and related disorders. Mol Chem Neuropathol. 1996; 28(1-3): 77-81.

[57] Odell D, Maciulis A, Cutler A, Warren L, McMahon WM, Coon H. et al. Confirmation of the association of the C4B null allelle in autism. Hum Immunol. 2005; 66(2): 140145.

[58] Momeni N, Brudin L, Behnia F, Nordstrom B, YosefiOudarji A, Sivberg B. et al. High complement factor I activity in the plasma of children with autism spectrum disorders. Autism Res Treat. 2012; 2012: 868576.

[59] Corbett BA, Kantor AB, Schulman H, Walker WL, Lit L, Ashwood P. et al. A proteomic study of serum from children with autism showing differential expression of apolipoproteins and complement proteins. Mol Psychiatry. 2007; 12(3): 292-306.

[60] Torres AR, Westover JB, Gibbons C, Johnson RC, Ward DC. Activating killer-cell immunoglobulin-like receptors (KIR) and their cognate HLA ligands are significantly increased in autism. Brain Behav Immun. 2012; 26(7): 1122-1127.

[61] Enstrom AM, Lit L, Onore CE, Gregg JP, Hansen RL, Pessah IN. et al. Altered gene expression and function of peripheral blood natural killer cells in children with autism. Brain Behav Immun. 2009; 23(1): 124-133.

[62] Vojdani A, Mumper E, Granpeesheh D, Mielke L, Traver $\mathrm{D}$, Bock K. et al. Low natural killer cell cytotoxic activity in autism: The role of glutathione, IL-2 and IL-15. J Neuroimmunol. 2008; 205(1-2): 148-154.

[63] Sweeten TL, Posey DJ, McDougle CJ. High blood monocyte counts and neopterin levels in children with autistic disorder. Am J Psychiatry. 2003; 160(9): 1691-1693.

[64] Enstrom AM, Onore CE, Van de Water JA, Ashwood P. Differential monocyte responses to TLR ligands in children with autism spectrum disorders. Brain Behav Immun. 2010; 24(1): 64-71.

[65] Ingersoll MA, Platt AM, Potteaux S, Randolph GJ. Monocyte trafficking in acute and chronic inflammation. Trends Immunol. 2011; 32(10): 470-477.

[66] Serbina NV, Jia T, Hohl TM, Pamer EG. Monocyte-mediated defense against microbial pathogens. Annu Rev Immunol. 2008; 26: 421-452

[67] Davoust N, Vuaillat C, Androdias G, Nataf S. From bone marrow to microglia: Barriers and avenues. Trends Immunol. 2008; 29(5): 227-234.

[68] Vargas DL, Nascimbene C, Krishnan C, Zimmerman AW, Pardo CA. Neuroglial activation and neuroinflammation in the brain of patients with autism. Ann Neurol. 2005; 57(1): 67-81.

[69] Theoharides TC, Angelidou A, Alysandratos KD, Zhang B, Asadi S, Francis K. et al. Mast cell activation and autism. Biochim Biophys Acta. 2012; 1822(1): 34-41.

[70] Angelidou A, Francis K, Vasiadi M, Alysandratos KD, Zhang B, Theoharides A. et al. Neurotensin is increased in serum of young children with autistic disorder. J Neuroinflammation. 2010; 7: 48 .
[71] Zhang B, Angelidou A, Alysandratos KD, Vasiadi M, Francis K, Asadi S, et al. Mitochondrial DNA and antimitochondrial antibodies in serum of autistic children. J Neuroinflammation. 2010; 7: 80

[72] Brown AS. Epidemiologic studies of exposure to prenata infection and risk of schizophrenia and autism. Dev Neurobiol. 2012; 72(10): 1272-1276.

[73] Michel M, Schmidt MJ, Mirnics K. Immune system gene dysregulation in autism and schizophrenia. Dev Neurobiol. 2012; 72(10): 1277-1287.

[74] Jung JY, Kohane IS, Wall DP. Identification of autoimmune gene signatures in autism. Transl Psychiatry. 2011; 1: e63.

[75] Voineagu I, Wang X, Johnston P, Lowe JK, Tian Y, Horvath S. et al. Transcriptomic analysis of autistic brain reveals convergent molecular pathology. Nature. 2011; 474(7351): 380-384.

[76] Garbett K, Ebert PJ, Mitchell A, Lintas C, Manzi B, Mirnics $\mathrm{K}$, et al. Immune transcriptome alterations in the temporal cortex of subjects with autism. Neurobiol Dis. 2008; 30(3): 303-311.

[77] Ziats MN, Rennert OM. Expression profiling of autism candidate genes during human brain development implicates central immune signaling pathways. PLoS ONE. 2011; 6(9): e24691.

[78] Miller BJ, Buckley P, Seabolt W, Mellor A, Kirkpatrick B. Meta-analysis of cytokine alterations in schizophrenia: Clinical status and antipsychotic effects. Biol Psychiatry. 2011; 70(7): 663-671.

[79] Depino AM. Peripheral and central inflammation in autism spectrum disorders. Mol Cell Neurosci. 2013; 53: 69-76.

[80] Comi AM, Zimmerman AW, Frye VH, Law PA, Peeden JN. Familial clustering of autoimmune disorders and evaluation of medical risk factors in autism. J Child Neurol. 1999; 14(6): 388-394.

[81] Hsiao EY, Patterson PH. Activation of the maternal immune system induces endocrine changes in the placenta via IL-6. Brain Behav Immun. 2011; 25(4): 604-615.

[82] Arrode-Bruses G, Bruses JL. Maternal immune activation by poly(I:C) induces expression of cytokines IL-1beta and IL-13, chemokine MCP-1 and colony stimulating factor VEGF in fetal mouse brain. J Neuroinflammation. 2012; 9: 83 .

[83] Smith SE, Li J, Garbett K, Mirnics K, Patterson PH. Maternal immune activation alters fetal brain development through interleukin-6. J Neurosci. 2007; 27(40): 10695 10702 .

[84] Malkova NV, Yu CZ, Hsiao EY, Moore MJ, Patterson $\mathrm{PH}$. Maternal immune activation yields offspring displaying mouse versions of the three core symptoms of autism. Brain Behav Immun. 2012; 26(4): 607-616.

[85] Schwartzer JJ, Careaga M, Onore CE, Rushakoff JA, Berman RF, Ashwood P. Maternal immune activation and strain specific interactions in the development of autism-like behaviors in mice. Transl Psychiatry. 2013; 3: e240.

[86] Soumiya H, Fukumitsu H, Furukawa S. Prenatal immune challenge compromises the normal course of neurogenesis during development of the mouse cerebral cortex. J Neurosci Res. 2011; 89(10): 1575-1585.

[87] Soumiya H, Fukumitsu H, Furukawa S. Prenatal immune challenge compromises development of upper-layer but not deeper-layer neurons of the mouse cerebral cortex. J Neurosci Res. 2011; 89(9): 1342-1350.

[88] Willette AA, Lubach GR, Knickmeyer RC, Short SJ, Styner $\mathrm{M}$, Gilmore $\mathrm{JH}$. et al. Brain enlargement and increased behavioral and cytokine reactivity in infant monkeys fol- 
lowing acute prenatal endotoxemia. Behav Brain Res. 2011; 219(1): 108-115.

[89] Baharnoori M, Bhardwaj SK, Srivastava LK. Effect of maternal lipopolysaccharide administration on the development of dopaminergic receptors and transporter in the rat offspring. PLoS ONE. 2013; 8(1): e54439.

[90] Oskvig DB, Elkahloun AG, Johnson KR, Phillips TM, Herkenham M. Maternal immune activation by LPS selectively alters specific gene expression profiles of interneuron migration and oxidative stress in the fetus without triggering a fetal immune response. Brain Behav Immun. 2012; 26(4): 623-634.

[91] Hsiao EY, McBride SW, Chow J, Mazmanian SK, Patterson $\mathrm{PH}$. Modeling an autism risk factor in mice leads to permanent immune dysregulation. Proc Natl Acad Sci USA. 2012; 109(31): 12776-12781.

[92] Rosen NJ, Yoshida CK, Croen LA. Infection in the first 2 years of life and autism spectrum disorders. Pediatrics. 2007; 119(1): e61-e69.

[93] Atladottir HO, Henriksen TB, Schendel DE, Parner ET Using maternally reported data to investigate the association between early childhood infection and autism spectrum disorder: The importance of data source. Paediatr Perinat Epidemiol. 2012; 26(4): 373-385.

[94] Abdallah MW, Larsen N, Mortensen EL, Atladottir HO, Norgaard-Pedersen B, Bonefeld-Jorgensen EC. et al Neonatal levels of cytokines and risk of autism spectrum disorders: An exploratory register-based historic birth cohort study utilizing the Danish Newborn Screening Biobank. J Neuroimmunol. 2012; 252(1-2): 75-82.

[95] Jyonouchi $\mathrm{H}$. Non-IgE mediated food allergy - update of recent progress in mucosal immunity. Inflamm Allergy Drug Targets. 2012; 11(5): 382-396

[96] Niehus R, Lord C. Early medical history of children with autism spectrum disorders. J Dev Behav Pediatr. 2006; 27(2 Suppl): S120-S127.

[97] Adams JB, Holloway CE, George F, Quig D. Analyses of toxic metals and essential minerals in the hair of Arizona children with autism and associated conditions, and their mothers. Biol Trace Elem Res. 2006; 110(3): 193-209.

[98] Adams JB, Romdalvik J, Ramanujam VM, Legator MS Mercury, lead, and zinc in baby teeth of children with autism versus controls. J Toxicol Environ Health A. 2007; 70(12): 1046-1051.

[99] Adams JB, Romdalvik J., Levine K.E., and Hu L.W. Mercyry in first-cut baby hair of children with autism versus typically-developing children. Toxicol Environ Chemist. [article]. 2008; 90(4): 739-753.

[100] Mayer EA. Gut feelings: The emerging biology of gut-brain communication. Nat Rev Neurosci. 2011; 12(8): 453-466.

[101] Cryan JF, O'Mahony SM. The microbiome-gut-brain axis: From bowel to behavior. Neurogastroenterol Motil. 2011; 23(3): 187-192.

[102] Lyte M, Varcoe JJ, Bailey MT. Anxiogenic effect of subclinical bacterial infection in mice in the absence of overt immune activation. Physiol Behav. 1998; 65(1): 63-68.

[103] Goehler LE, Gaykema RP, Opitz N, Reddaway R, Badr $\mathrm{N}$, Lyte M. Activation in vagal afferents and central autonomic pathways: Early responses to intestinal infection with
Campylobacter jejuni. Brain Behav Immun. 2005; 19(4): 334-344.

[104] Bercik P, Collins SM, Verdu EF. Microbes and the gut-brain axis. Neurogastroenterol Motil. 2012; 24(5): 405-413.

[105] Adams JB, Johansen LJ, Powell LD, Quig D, Rubin RA. Gastrointestinal flora and gastrointestinal status in children with autism-comparisons to typical children and correlation with autism severity. BMC Gastroenterol. 2011; 11: 22.

[106] Kushak RI, Lauwers GY, Winter HS, Buie TM. Intestinal disaccharidase activity in patients with autism: Effect of age, gender, and intestinal inflammation. Autism. 2011; 15(3): 285-294.

[107] Williams BL, Hornig M, Buie T, Bauman ML, Cho Paik $\mathrm{M}$, Wick I. et al. Impaired carbohydrate digestion and transport and mucosal dysbiosis in the intestines of children with autism and gastrointestinal disturbances. PLoS ONE. 2011; 6(9): e24585.

[108] MacFabe DF, Cain NE, Boon F, Ossenkopp KP, Cain DP. Effects of the enteric bacterial metabolic product propionic acid on object-directed behavior, social behavior, cognition, and neuroinflammation in adolescent rats: Relevance to autism spectrum disorder. Behav Brain Res. 2011; 217(1): 47-54.

[109] Ossenkopp KP, Foley KA, Gibson J, Fudge MA, Kavaliers M, Cain DP. et al. Systemic treatment with the enteric bacterial fermentation product, propionic acid, produces both conditioned taste avoidance and conditioned place avoidance in rats. Behav Brain Res. 2012; 227(1): 134-141.

[110] El-Ansary AK, Ben Bacha A, Kotb M. Etiology of autistic features: The persisting neurotoxic effects of propionic acid. J Neuroinflammation. 2012; 9: 74.

[111] Ashwood P, Wakefield AJ. Immune activation of peripheral blood and mucosal $\mathrm{CD}^{+}$lymphocyte cytokine profiles in children with autism and gastrointestinal symptoms. J Neuroimmunol. 2006; 173(1-2): 126-134.

[112] Ashwood P, Anthony A, Torrente F, Wakefield AJ. Spontaneous mucosal lymphocyte cytokine profiles in children with autism and gastrointestinal symptoms: Mucosal immune activation and reduced counter regulatory interleukin-10. J Clin Immunol. 2004; 24(6): 664-673.

[113] Jyonouchi H, Geng L, Ruby A, Reddy C, Zimmerman-Bier B. Evaluation of an association between gastrointestinal symptoms and cytokine production against common dietary proteins in children with autism spectrum disorders. J Pediatr. 2005; 146(5): 605-610.

[114] Burks AW, Tang M, Sicherer S, Muraro A, Eigenmann PA, Ebisawa M. et al. ICON: Food allergy. J Allergy Clin Immunol. 2012; 129(4): 906-920.

[115] Boyce JA, Assa'ad A, Burks AW, Jones SM, Sampson HA, Wood RA. et al. Guidelines for the diagnosis and management of food allergy in the United States: Report of the NIAID-sponsored expert panel. J Allergy Clin Immunol. 2010; 126(6 Suppl): S1-S58.

[116] Glatt SJ, Tsuang MT, Winn M, Chandler SD, Collins M, Lopez L. et al. Blood-based gene expression signatures of infants and toddlers with autism. J Am Acad Child Adolesc Psychiatry. 2012; 51(9): 934-944 e2. 